\title{
Unusual NHC-Iridium(I) Complexes and their Use in the Intramolecular Hydroamination of Unactivated Aminoalkenes
}

\author{
Gellért Sipos, ${ }^{[a]}$ Arnold Ou, ${ }^{[a]}$ Brian W. Skelton, ${ }^{[b]}$ Laura Falivene ${ }^{[c]}$ Luigi Cavallo, ${ }^{*[c]}$ Reto Dorta ${ }^{*}[a]$
}

\begin{abstract}
NHC ligands with naphthyl side chains were employed for the synthesis of unsaturated, yet isolable $[(\mathrm{NHC}) \operatorname{lr}(\mathrm{COD})]^{+}$ complexes. These compounds are stabilized by an interaction of the aromatic wingtip that leads to a sideways tilt of the NHC-Ir bond. Detailed studies show how the tilting of such $\mathrm{N}$-heterocyclic carbenes affects the electronic shielding properties of the carbene carbon and how this is reflected by significant upfield shifts in the ${ }^{13} \mathrm{C}$ NMR signals. When employed in the intramolecular hydroamination, these $[(\mathrm{NHC}) \operatorname{Ir}(\mathrm{COD})]^{+}$species show very high catalytic activity under mild reaction conditions. An enantiopure version of the catalyst system produces pyrrolidines with excellent enantioselectivities.
\end{abstract}

\section{Introduction}

Homogeneous catalysis based on metal complexes where bulky, monodentate ancillary ligands are used has gained enormous significance in the last two decades because it often provides catalytic systems with superior performance. For example, major developments in cross-coupling reactions have often relied on substituting multiple ligands or ligand chelates with a single, sterically demanding spectator ligand. ${ }^{[1]}$ While the success of this approach is undeniable as it usually generates highly active and unsaturated metal complexes as catalytic species, rendering ligand systems overly bulky can lead to catalyst decomposition via unwanted activations of parts of the ligand that closely approach the metal center. ${ }^{[2]}$

Within the growing class of bulky, monodentate ancillary ligands, Arduengo-type $\mathrm{N}$-heterocyclic carbenes (NHC) have garnered increasing attention and have become ubiquitous ligands in transition metal catalysis. ${ }^{[3,4,5]}$ Due to their strong $\sigma$-donor ability and high stability of their metal complexes they represent powerful tools in modern homogeneous catalyst development. Although dozens of monodentate NHCs have been synthesized to date, only a few of them have so far proven to be versatile as ancillary ligands. Data gathered so far would indicate that NHCs with perpendicularly oriented aromatic side chains offer a

\footnotetext{
[a] Prof. Reto Dorta, Gellért Sipos, Arnold Ou

School of Chemistry and Biochemistry

University of Western Australia

35 Stirling Highway, 6009 Crawley, WA, Australia

E-mail: reto.dorta@uwa.edu.au

[b] Prof. Brian W. Skelton

Centre for Microscopy, Characterisation and Analysis

University of Western Australia

35 Stirling Highway, 6009 Crawley, WA, Australia

[c] Prof. Luigi Cavallo, Dr. Laura Falivene

Kaust Catalysis Center, Physical Sciences and Engineering Division

King Abdullah University of Science and Technology

Thuwal 23955-6900, Saudi Arabia
}

uniquely useful steric environment as exemplified by the very successful IPr/SIPr and IMes/SIMes ligand pairs. ${ }^{[5]}$

In the past, we have identified NHCs with alkylated naphthyl wingtips as viable and often superior alternatives to these ligands. ${ }^{[6]}$ In general, our ligands show increased reactivity also under forcing reaction conditions, which would point to less ready deactivation of the catalyst through unwanted metal-ligand reactivity. Even within this new class of NHCs, fine-tuning of the ligands' naphthyl side chain substituents seems to be important. For example, when used as ligands in ruthenium metathesis, the particular substitution pattern of the side chains rendered the catalyst system more or less prone to decomposition through what appeared to be ruthenium-mediated cyclometalation reactions. ${ }^{[6]]}$ In another study on their application to NHC-Pd catalysts, the special steric bulk created by these ligands resulted in greatly improved reactivity in the Suzuki-Miyaura coupling reaction of sterically hindered aryls. ${ }^{[6 \mathrm{~d}]}$

Herein, we disclose studies that show how two representative members of our ligand systems ( $\mathbf{1 a}$ and $\mathbf{1 b}$ on Scheme 1), while electronically very comparable to the classical IPr/SIPr and IMes/SIMes ligands, are able to stabilize formally three coordinate $[\mathrm{NHC}-\mathrm{Ir}]^{+}$systems through weak, non-destructive interactions of their side chains with the metal center. ${ }^{[7]}$ We also show why and how the tilted nature of such NHC-M structures leads to a significant upfield shifts in the ${ }^{13} \mathrm{C}$ NMR signals. These unsaturated $[\mathrm{NHC}-\mathrm{Ir}]^{+}$species were then used in the intramolecular hydroamination (HA) of simple aminoalkenes, ${ }^{[8]}$ where developments within the last decade have established the usefulness of group 9 metal complexes in the intramolecular HA of electronically unbiased aminoalkenes. ${ }^{[9]}$ Most notably, Hartwig et al. have developed cationic rhodium systems that contain phosphorous-based ancillary ligands, ${ }^{[9,, g, i]}$ while Stradiotto et al. have reported the use of simple $[\operatorname{Ir}(\mathrm{COD}) \mathrm{Cl}]_{2}$ as the precatalyst. ${ }^{[9 c, e]}$ These developments have broadened the scope of this simple and atom-economical reaction as they employ relatively easy-to-handle, functional group tolerant late-transition metal catalysts for the construction of these important nitrogen heterocycles. Obviously, developing enantioselective versions of this transformation represents a particular challenge with any chiral ligand-metal combination. ${ }^{[9 f, 10]}$ While monodentate NHCs have not been previously used in the HA reaction of unactivated aminoalkenes, ${ }^{[11]}$ we show how our special ligand architecture imparts unusually high reactivity and how we can extend their use to the asymmetric version of this reaction, where systems based on iridium have been absent so far. ${ }^{[12]}$ 


\section{Results and Discussion}

\subsection{Synthesis and characterization of NHC- iridium complexes.}

Scheme 1 shows the synthetic pathway to neutral NHC-Ir systems employing two representatives of our $\mathrm{NHC}$ ligand family [2-SICyNap (1a) and 2,7-SICyNap (1b)]. The (NHC)Ir(COD)Cl complexes $\mathbf{2 a}$ and $\mathbf{2} \mathbf{b}$ were obtained in good overall yields by reacting stoichiometric amounts of the free carbenes with 0.5 equiv. $\left[\operatorname{Ir}(\mathrm{COD}) \mathrm{Cl}_{2}\right.$ (Scheme 1). The syn- and anti-isomers of $2 \mathrm{a}$ were separated by column chromatography.

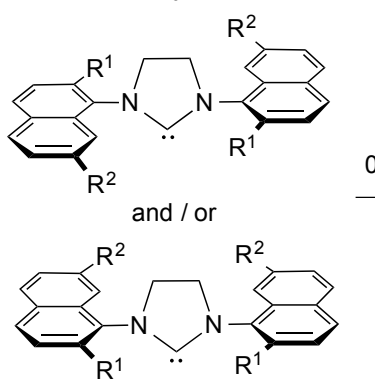

1a $\left(\mathrm{R}^{1}=\mathrm{C}_{6} \mathrm{H}_{11}, \mathrm{R}^{2}=\mathrm{H}\right)$; anti: syn $=3: 1$

1b $\left(\mathrm{R}^{1}, \mathrm{R}^{2}=\mathrm{C}_{6} \mathrm{H}_{11}\right)$; $>95 \%$ anti

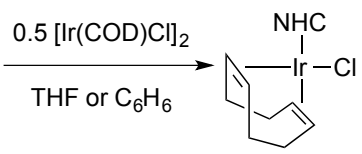

$$
\begin{gathered}
\text { syn-2a }(19 \%) \\
\text { anti-2a }(60 \%) \\
\text { anti-2b }(94 \%) \\
\text { CO (g), } \\
\mathrm{DCM}
\end{gathered}
$$

anti-3a $(89 \%)$ anti-3b $(84 \%)$

Scheme 1. Synthesis of neutral NHC-Ir(I) complexes.

The ${ }^{1} \mathrm{H}$ and the ${ }^{13} \mathrm{C}$ NMR spectra of anti-2a and anti-2b exhibit two distinct sets of signals for each of the naphthyl side chains (i.e. twenty carbon signals can be observed). The two methylene carbon atoms of the imidazolidine backbone are clearly distinguishable in these complexes ( 54.8 and $54.4 \mathrm{ppm}$ for anti2a; 54.5 and $54.0 \mathrm{ppm}$ for anti-2b). Also, the $\mathrm{CH}=\mathrm{CH}$ fragments of the COD ligand are represented by four distinct sets of signals both in the ${ }^{1} \mathrm{H}$ and ${ }^{13} \mathrm{C}$ NMR spectra. Finally, the most characteristic resonance ( $\mathrm{NHC}$ carbene) in the ${ }^{13} \mathrm{C}$ NMR spectra is found at around $210 \mathrm{ppm}$.

The synthesis and full characterization of complexes 2 (molecular structures shown in Figure 1) set the stage to evaluate the electronic properties of our NHC ligands $\mathbf{1 a}$ and $\mathbf{1 b}$. The carbonyl complexes were accessed in high yield by reacting anti-2a and anti-2b with carbon monoxide. ${ }^{[13]}$ Somewhat expectedly, anti-3a and anti-3b showed TEP values very similar to the established SIMes/IMes and SIPr/IPr ligand pairs (Table 1). ${ }^{[14]}$ However, we note that the second cyclohexyl substituent (position 7) is rendering ligand $\mathbf{1 b}$ more electron-donating, much

\begin{tabular}{|c|c|c|c|}
\hline NHC & $v_{\mathrm{CO}}\left(\mathrm{cm}^{-1}\right)$ & $v_{\mathrm{CO}^{\mathrm{av}}}\left(\mathrm{cm}^{-1}\right)$ & $\operatorname{TEP}\left(\mathrm{cm}^{-1}\right)$ \\
\hline 2-SICyNap (1a) & $2067.4,1982.7$ & 2025.0 & $2051.2^{[a]}$ \\
\hline 2,7-SICyNap (1b) & $2066.5,1981.3$ & 2023.9 & $2050.3^{[a]}$ \\
\hline SIPr ${ }^{[b]}$ & $2068.0,1981.8$ & 2024.9 & 2051.2 \\
\hline $\operatorname{IPr}[\mathrm{b}]$ & $2066.8,1981.0$ & 2023.9 & 2050.2 \\
\hline SIMes ${ }^{[b]}$ & $2068.0,1981.2$ & 2024.6 & 2050.8 \\
\hline $\mathrm{IMes}^{[\mathrm{b}]}$ & $2066.4,1979.8$ & 2023.1 & 2049.6 \\
\hline
\end{tabular}
in the same way as seen when going from the saturated to the unsaturated NHC analogues of standard ligands SIMes/IMes and SIPr/IPr.

Table 1. Carbonyl stretching frequencies for complexes $(\mathrm{NHC}) \operatorname{Ir}(\mathrm{CO})_{2} \mathrm{Cl}$ and $(\mathrm{NHC}) \mathrm{Ni}(\mathrm{CO})_{3}$

[a] Calculated with the formula: TEP $=0.847 \times v^{\text {average }}+336\left[\mathrm{~cm}^{-1}\right]$.

[b] Taken from ref. [14d]

$(\mathrm{NHC}) \operatorname{Ir}(\mathrm{COD}) \mathrm{Cl}$ complexes syn-2a, anti-2a and anti-2b also gave us a very interesting entry into ligand degradation problems mentioned in the introduction. In a recent paper, Aldridge et al. had studied the outcome of the reaction of $(\mathrm{IPr}) \operatorname{Ir}(\mathrm{COD}) \mathrm{Cl}$ with $\mathrm{Na}\left(\mathrm{BAr}_{4}^{f}\right),{ }^{[15,16]}$ where abstraction of the chloride led to a highly reactive metal species that underwent ready $\mathrm{C}-\mathrm{H}$ activation and dehydrogenation of one of the isopropyl moieties of the wingtips. In stark contrast, halide abstraction on syn-2a, anti-2a and anti-2b gave deep red, crystalline materials where X-ray diffraction analyses of syn-4a, anti-4a and anti-4b confirmed the composition of the complexes as being $[(\mathrm{NHC}) \operatorname{Ir}(\mathrm{COD})]\left[\mathrm{PF}_{6}\right]$ (Scheme 2). ${ }^{[17]}$ Representations of anti-4a and anti-4b (Figure 1) reveal that cyclometalation does not occur and in order to stabilize these formally 14-electron species, ${ }^{[18]}$ one of the aromatic wingtips approaches the metal center and displays an arene-metal interaction that involves the C8 and C8a carbon atoms of the naphthyl unit [C58 and C58A in the crystallographic numbering; Ir-C distances are 2.407(1) $\AA$ /

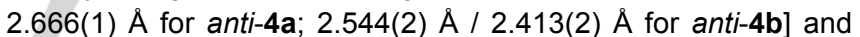
leads to a pseudo-square planar coordination geometry. ${ }^{[19]}$ As a consequence, the $\mathrm{NHC}$ ring is tilted towards the side where the interaction occurs. ${ }^{[20]}$ This affords disparate Ir-C1-N2 and Ir-C1N5 angles [134.56(8) $)^{\circ} / 116.00(8)^{\circ}$ for anti-4a; 145.0(1) / $106.7(1)^{\circ}$ for anti-4b] and also impacts space occupation around the metal center. As evidenced by the steric quadrant maps shown in Figure 2, the tilting results in a $\% \mathrm{~V}_{\text {Bur }}$ of $~ 80 \%$ of the relevant quadrant and leads to a significant increase in overall ligand bulk.

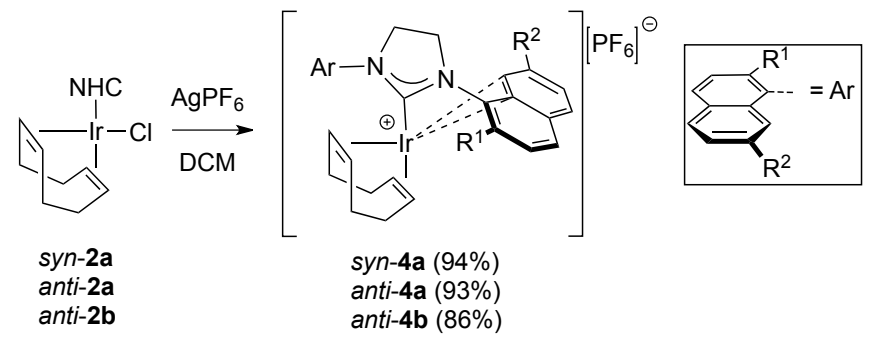

Scheme 2. Synthesis of cationic NHC-Ir(I) complexes. 


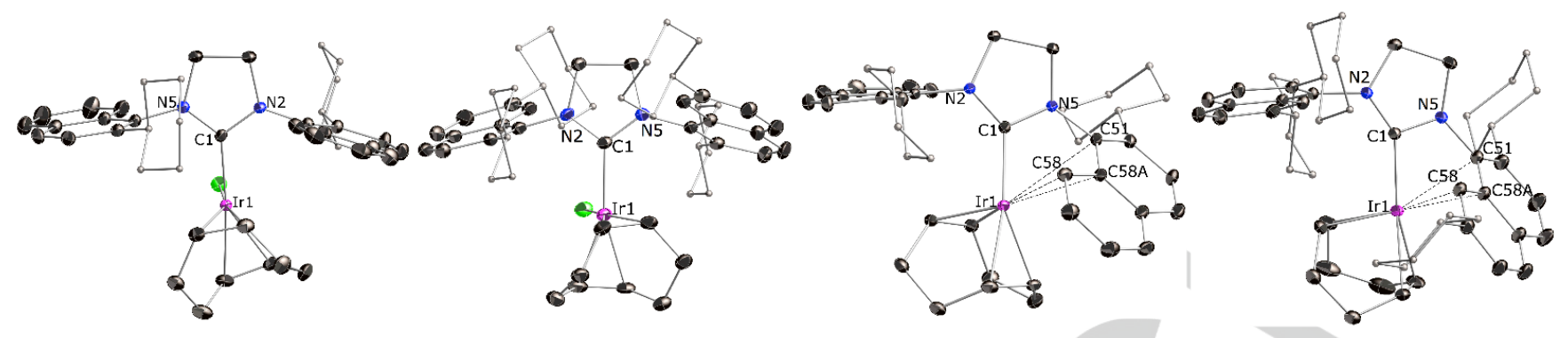

Figure 1. Molecular structures of (from left to right) anti-2a, anti-2b, anti-4a and anti-4b. For cationic complexes, the anion is omitted for clarity. All hydrogens are omitted for clarity and the cyclohexyl groups are represented differently for the same reason. Selected bond lengths and angles: for anti-2a Ir-C1 2.034(1), Ir-C11 2.147(1), Ir-C12 2.147(1), Ir-C15 2.127(1), Ir-C16 2.094(1), Ir-Cl 2.3645(3), Ir-C1-N2 120.70(9), Ir-C1-N5 131.31(9); for anti-2b Ir-C1 2.052(5), Ir-C11 2.194(5), IrC12 2.173(6), Ir-C15 2.121(5), Ir-C16 2.113(6), Ir-Cl 2.350(1), Ir-C1-N2 126.0(4), Ir-C1-N5 127.2(4); for anti-4a Ir-C1 2.041(1), Ir-C11 2.178(1), Ir-C12 2.233(1), Ir-C15 2.101(1), Ir-C16 2.104(1), Ir-C51 2.981(1), Ir-C58 2.407(1), Ir-C58A 2.666(1), Ir-C1-N2 134.56(9), Ir-C1-N5 116.00(8); for anti-4b Ir-C1 2.038(2), Ir-C11 2.181(2), Ir-C12 2.224(2), Ir-C15 2.091(2), Ir-C16 2.114(2), Ir-C51 2.591(1), Ir-C58 2.544(2), Ir-C58A 2.413(2), Ir-C1-N2 145.0(1), Ir-C1-N5 106.7(1).
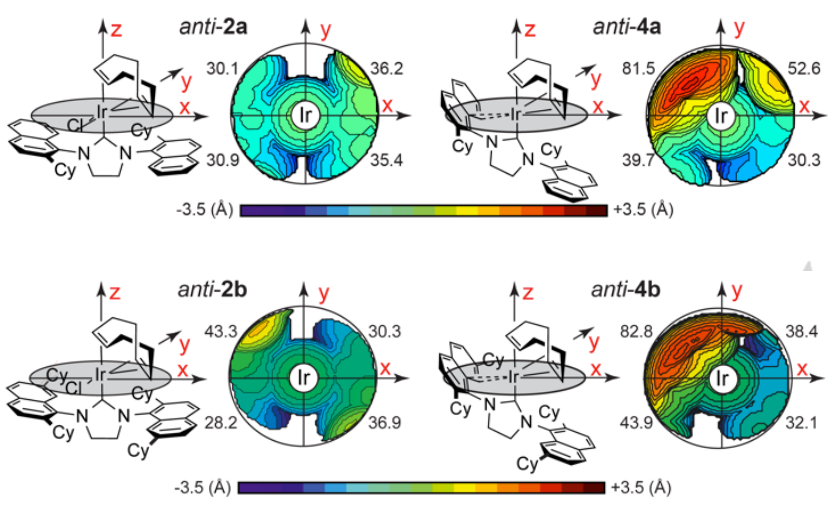

Figure 2. Steric maps of neutral anti-2a / anti-2b and cationic anti-4a / anti-4b. Isocontour lines in $\AA$.

NMR spectroscopy indicated that the arene interaction might not be present in solution. The proton spectra of anti-4a and anti-4b were highly simplified compared to the parent neutral complexes and the two naphthyl rings appeared to be identical on the ${ }^{1} \mathrm{H}$ NMR time scale. Nevertheless, the ${ }^{1} \mathrm{H}$ NMR analysis of the syn4a isomer at $298 \mathrm{~K}$ showed very broad signals, and a VT analysis of anti-4b, while inconclusive, indicated that both the $\mathrm{COD}$ and NHC ligands undergo fluxional processes. More insightful information was gathered through analyses of the ${ }^{13} \mathrm{C}$ NMR spectra. The signals for the C8 and C8a carbons of the two naphthyl rings showed broad singlets significantly upfield with respect to their neutral counterparts $\left(\delta_{\mathrm{c} 8}=107.2 / \delta_{\mathrm{c} 8 \mathrm{a}}=\right.$ $126.0 \mathrm{ppm}$ for anti-4a; $\delta_{\mathrm{C} 8}=107.0 / \delta_{\mathrm{C} 8 \mathrm{a}}=123.6$ for anti-4b), which would be expected when binding interactions with the metal are present. Unusually large shifts were also measured for the carbene carbons, whose signals are positioned $\sim 20 \mathrm{ppm}$ upfield from their neutral congeners [196.0 ppm (anti-4a) and $188.1 \mathrm{ppm}$ (anti-4b)]. At first sight, we attributed these large shifts to the tilt of the $\mathrm{N}$-heterocycle that is maintained in solution and influences the electronic environment of the carbene carbon. Evidence for such a scenario came from an experiment whereby anti-4b was dissolved in $\mathrm{CD}_{3} \mathrm{CN}$. A new, dissymmetric species $\left[\left(\right.\right.$ anti-1b) $\left.\operatorname{Ir}(\mathrm{COD})\left(\mathrm{CD}_{3} \mathrm{CN}\right)\right]\left[\mathrm{PF}_{6}\right]$ was formed with NMR data mirroring the ones seen for anti-2b and where the carbene carbon was found at 200.5 ppm. ${ }^{\text {[21] }}$

\subsection{Computational analysis of tilted NHC-M compounds.}

To shed light on the origin of the upfield shift of the carbene carbons in our tilted structures, we performed DFT NMR calculations. ${ }^{[13,22]}$ We initially tested the computational setup to reproduce the crystallographic geometry and the experimental chemical shift, $\delta \mathrm{C}$, of 12 monodentate and chelating NHC-M complexes described in the literature, ${ }^{[20 b, 23]}$ see Figure S11, plus the free $\mathrm{NHC} \mathbf{1 b}$ and the corresponding protonated form, $\mathbf{1} \mathbf{b} \bullet \mathrm{H}^{+}$. We selected these compounds because they represent pairs of related complexes presenting linear and bent NHC-M bonds, for which the crystallographic structure and ${ }^{13} \mathrm{C}$ NMR data are available.

To check for the validity of the chosen computational approach in reproducing the geometry of the complexes examined, we compared the main structural parameters from the DFT optimization, which is the M-NHC bond distance and the M-C$\mathrm{N}(\mathrm{NHC})$ angles, with the values in the crystallographic structure, see Table S2. The excellent agreement between the DFT optimized and the crystallographic parameters, with mean unsigned error on the M-NHC distance of only $0.013 \AA$, and on the $\mathrm{M}-\mathrm{C}-\mathrm{N} 1$ and $\mathrm{M}-\mathrm{C}-\mathrm{N} 2$ angles of $0.81^{\circ}$ and $1.04^{\circ}$, validate the methodology we used to calculate geometries of this series of $\mathrm{M}-\mathrm{NHC}$ complexes. To check for the validity of the chosen DFTNMR protocol, we tested it to reproduce the experimental $\delta_{C}$ of the examined complexes. The excellent correlation $\left(R^{2}=0.93\right)$ between the DFT isotropic chemical shielding $\sigma_{C}$ and the experimental $\delta_{C}$ of the carbene $C$, see Figure $S 12$, validates the DFT-NMR part of the computational setup.

At this point, we moved to decipher the origin of the upfield shift due to the bending of the M-NHC bond. To this end, we used the model system NHC-Se of Figure 3, since it was demonstrated that the NHC-Se bond is a good mimic of the NHC-M bond. ${ }^{[22,24]}$ 
Starting from a linear geometry, we tilted the NHC-Se bond by $\theta$ $=10^{\circ}, 20^{\circ}$ and $30^{\circ}$. For each structure we calculated the $\sigma_{c}$ of the carbene atom. Gratifyingly, also the $\sigma_{C}$ of the NHC-Se system moves upfield as the NHC-Se bond is tilted (Figure 3), and the shift, $\sim 10 \mathrm{ppm}$, is consistent with the experimental shift in the NHC-M complexes we investigated. The strong correlation $\left(R^{2}=0.90\right)$ between $\sigma_{C}$ and $\theta$ indicates that the upfield shift is essentially due to the tilting.

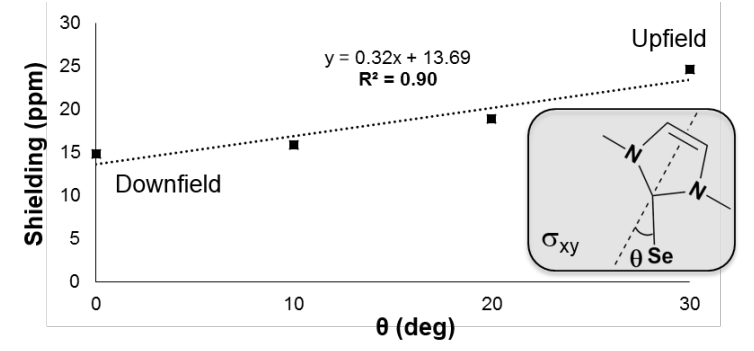

Figure 3. DFT chemical shielding versus tilt angle for NHC-Se.

Decomposing the isotropic chemical shielding $\sigma_{c}$ into dia- and paramagnetic terms, $\sigma_{\mathrm{c}}=\sigma_{\mathrm{d}}+\sigma_{\mathrm{p}}$, indicates that the change in $\sigma_{\mathrm{C}}$ is due to the paramagnetic term $\sigma_{\mathrm{p}}$ that varies by $6.5 \mathrm{ppm}$ from $0^{\circ}$ to $30^{\circ}$, while the diamagnetic term $\sigma_{d}$ varies by only 0.1 $\mathrm{ppm}$. The paramagnetic shielding depends from transition of electrons between occupied and virtual orbitals, properly connected by symmetry, induced by the external magnetic field (e.g. $p_{x} \rightarrow p_{z}$ by $90^{\circ}$ rotation around y). The amount of the shielding is inversely related to the energy gap between these two orbitals, and it is directly related to proper overlap of the orbitals after rotation. ${ }^{[25]}$ Correlation of the paramagnetic term to molecular properties thus should focus on these two factors, which affect the paramagnetic shielding.

Since $\sigma_{p}$ is dominated by transitions between symmetry-related occupied and empty molecular orbitals, $\mathrm{MOs},{ }^{[25]}$ based on previous work, ${ }^{[24 a]}$ we focused on changes in energy and shape of the filled and empty MOs corresponding to the $\sigma$ and $\pi^{*}$ Se$\mathrm{NHC}$ bond at $\theta=0^{\circ}$ and $30^{\circ} .{ }^{[13,25]}$ While the connection between the paramagnetic shielding and the energy gap between these MOs is quite simple, the smaller the gap the larger the shielding, the required symmetry-relation between the MOs is explained in Figure $4 \mathrm{a}$. In the linear geometry, rotation of the MO induced by the external magnetic field results in MOs having the same symmetry and optimal overlap, since the $\sigma$-bonding $\mathrm{MO}$ is mainly composed by $p_{x} A O s$ on both the carbenic atom and the Se atom, see Figure $4 \mathrm{a}$ and $4 \mathrm{~b}$. This optimal overlap results in strong magnetic coupling between the $\sigma$ and $\pi^{*}$ MOs, with strong paramagnetic deshielding of the carbenic $C$ atom. Differently, in the bent geometry the same rotation results in non-optimal overlap of the MOs, due to the a different composition of the $\sigma$ bonding $\mathrm{MO}$ on Se, see Figure $4 \mathrm{a}$ and $4 \mathrm{c}$. Due to the tilting, hybridization of the Se atoms moves from dominant participation of the $p_{x} A O$ to a mixture of $p_{x}$ and $p_{y} A O s$, in order to orient the $\sigma$-bonding lobe on Se towards the NHC, see Figure $4 c$. The $p_{x}$ component of the bonding lobe on Se still is capable of magnetic coupling with the $\pi^{*} \mathrm{MO}$ by $90^{\circ}$ rotation, whereas the $\mathrm{p}_{\mathrm{y}}$ component has not the proper symmetry, and thus does not contribute to the paramagnetic shielding. The reduced amount of the $p_{x}$ component in the NHC-Se $\sigma$-bond on going from linear to bent geometries results in weaker magnetic coupling between $\sigma$ and $\pi^{*}$ MOs in the bent geometries and, consequently, in smaller paramagnetic deshielding and upfield shift of the carbenic resonance. Extension of these concepts to a NHC-M complex is straightforward.

a)

L) Linear geometry, $\theta=0^{\circ}$
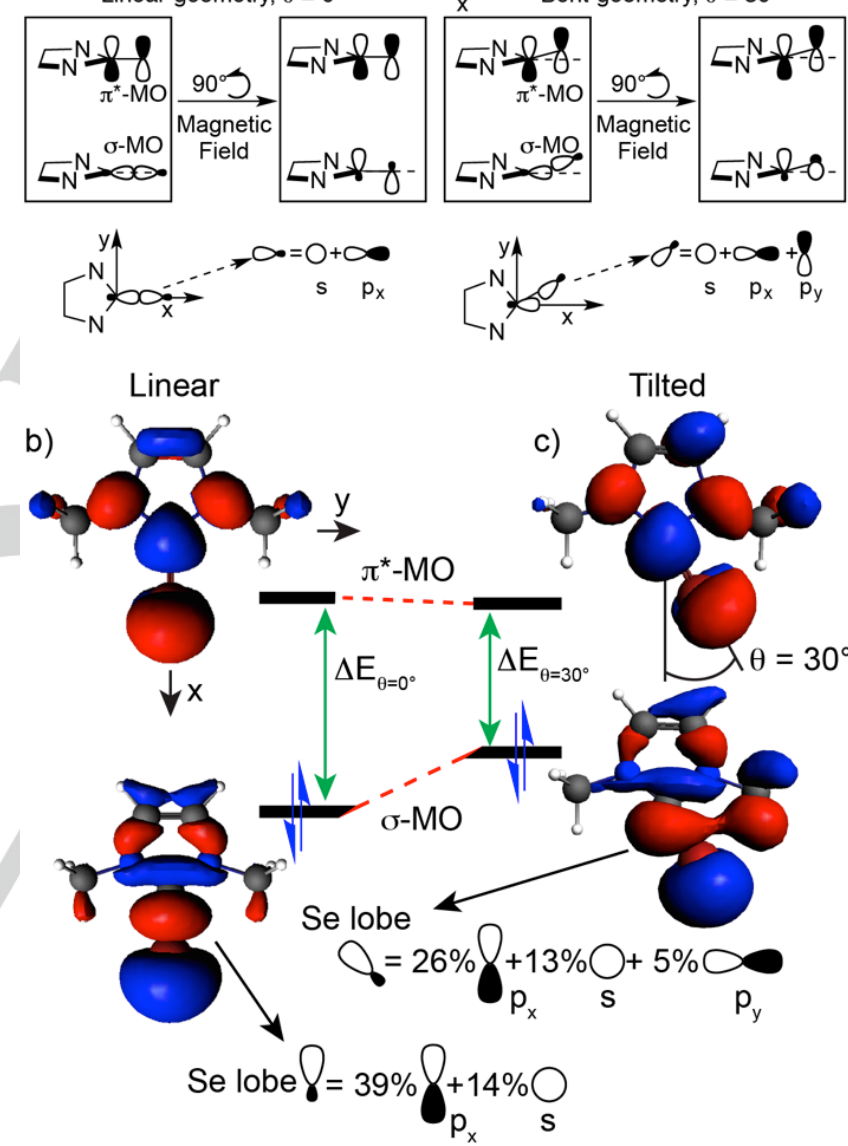

Figure 4. a) Schematic representation of the magnetic $\sigma \rightarrow \pi^{*}$ coupling. b), c) Analysis of the MOs corresponding to the $\sigma$ and $\pi^{*}$ Se-NHC bonds.

Quantitatively, our analysis indicates that a bending of $30^{\circ}$ of the NHC-Se bond destabilizes the M-NHC $\sigma$-bonding MO by 0.54 $\mathrm{eV}$, while the NHC-Se $\pi^{*} \mathrm{MO}$ is stabilized by $0.24 \mathrm{eV}$, with a decrease of $0.78 \mathrm{eV}$ of the energy gap between them (Figure S13). Representation of these MOs at $\theta=0^{\circ}$ and $30^{\circ}$ (Figure 4), suggests that destabilization of the NHC-Se $\sigma$-bonding $\mathrm{MO}$ is due to a misalignment of the in phase lobes on the $\mathrm{NHC}$ and the $\mathrm{Se}$ atom. Differently, the NHC-Se $\pi^{*} \mathrm{MO}$ is less affected because the tilting does not reduce the overlap of the $p_{z}$ orbitals on the carbene $\mathrm{C}$ and $\mathrm{Se}$ atoms. The reduced energy gap 
between the $\sigma$ and $\pi^{*}$ MOs should shift the carbene atom downfield. However, the weight of the $p_{x}$ atomic orbital on the Se atom in the NHC-Se $\sigma$-bonding $\mathrm{MO}$, which is the atomic orbital having proper symmetry relation for overlap with the NHC-Se $\pi^{*}$ MOs after $90^{\circ}$ rotation, is strongly reduced with tilting (from $39 \%$ to $26 \%$, see Figure 4 ). This translates into poorer magnetic coupling, and causes the observed upfield shift of the carbene atom. $^{[13]}$

\subsection{Catalytic application in the intramolecular hydroamination reaction.}

The catalytic behavior of complexes $\mathbf{4}$ was then explored in the intramolecular HA reaction. In a first stage, we tested cationic syn-4a, anti-4a and anti-4b with model substrate $\mathbf{5 a}$ and monitored their performance with ${ }^{1} \mathrm{H}$ NMR spectroscopy (Figure S8). Cyclization occurred with a catalyst loading of $0.5 \mathrm{~mol} \%$ at room temperature and an especially impressive performance was achieved with anti-4b, with full conversion attained within $\sim 3.5$ minutes (TOF of ca. $3500 \mathrm{~h}^{-1}$ ). Generating anti-4b in situ by mixing equimolar amounts of anti-2b and $\mathrm{AgPF}_{6}$ in $\mathrm{DCM}$ prior to adding substrate $\mathbf{5 a}$ replicated the results seen for preformed catalyst anti-4b. In stark contrast, using the similarly bulky and electronically analogous (Table 1) SIPr ligand [(SIPr)Ir(COD)Cl + $\mathrm{AgPF}_{6}$ ] led to a totally inefficient catalyst even when increasing the catalyst loading tenfold ( $5 \mathrm{~mol} \%$ ).

Subsequently, a variety of substrates were tested with anti-4b and results are summarized in Table 1. For these reactions, we chose ${ }^{\mathrm{t}} \mathrm{BuOH}$ as the solvent because not only did it show comparable reactivity with model subtrate $\mathbf{5 a}$, but reactions with other substrates gave less secondary products that arise from isomerization of the olefin moiety. Examples of successfully ringclosed substrates include a variety of electron donating and withdrawing benzyl groups which are tolerated and lead to high yields of product at low catalyst loadings of anti-4b (6-8). Substrates with aliphatic groups on the nitrogen went through the cyclization smoothly (9 and 10). Hydroamination of aryl amine (11a), which was described as a limitation for cationic rhodium systems, ${ }^{\left[{ }^{[9]}\right]}$ gave the corresponding pyrrolidine $(\mathbf{1 1 b})$ in good yield.

The backbone of the substrate can be modified to include a variety of substituents $(5,12-16)$ and while the Thorpe-Ingold effect clearly helps cyclization, substrate 16a that lacks backbone substitution underwent cyclization smoothly with higher catalyst loadings $(3.5 \mathrm{~mol} \%)$. This is in contrast to the simple $[\operatorname{Ir}(\mathrm{COD}) \mathrm{Cl}]_{2}$ system described by Stradiotto et al. ${ }^{[9 \mathrm{e}]}$ which is not able to cyclize this type of substrates. A higher catalyst loading of anti-4b was also needed for the formation of the 6-membered piperidine $\mathbf{1 8 b}$. Some limitations remain however under our chosen reaction conditions. For example, the cyclization of internal alkene $17 \mathbf{a}$ only led to trace amounts of the expected product $\mathbf{1 7 b}$, and what anti-4b shares with $\left[\operatorname{lr}(\mathrm{COD}) \mathrm{Cl}_{2}\right.$ is the inability to cyclize primary amines under these conditions (i.e. no additives). Overall though, the results listed in Table 2 show that surprisingly low catalyst loadings and mild reaction conditions can be used in the intramolecular HA with catalyst anti-4b.

Table 2. Scope of the intramolecular HA reaction catalyzed by anti-4b.

Substrate




\subsection{Asymmetric intramolecular hydroamination reaction.}

An intriguingly simple possibility to further extend the utility of our catalyst system arose from the fact that the NHCs used above can rather easily be modified to produce enantiopure ligand frameworks, as previously described by us. ${ }^{[26]}$ To this aim and to keep the overall catalytic system as similar as possible to anti-4a respectively anti-4b, we used a close relative of ligand 1a that we had previously used in a palladium-catalyzed asymmetric $\alpha$-arylation protocol. $^{[26 a]}$ The corresponding cationic complex $\left(R_{a}, R_{a}, S, S\right)-19$ (Table 3 ) was isolated in $52 \%$ overall yield (2 steps) from the corresponding $\mathrm{NHC}$ salt. The reactivity of 19 (for reasons unknown at present) was significantly lower when compared to its immediate counterpart anti-4a when monitoring the conversion of substrate 5a. Furthermore and in contrast to anti-4b, catalyst 19 did not react smoothly with substrates in ${ }^{\mathrm{t}} \mathrm{BuOH}$. Nevertheless, reactions run in $\mathrm{DCM}$ showed that ready cyclization occurs under mild conditions when raising the catalyst loading. Enantioselectivities that we recorded with the substrates chosen for this brief survey are excellent and indeed, the ee values obtained for these pyrrolidines are amongst the highest reported for the asymmetric intramolecular HA of unactivated aminoolefins. ${ }^{[27]}$ Furthermore, the fact that the present system seems to be rather insensitive to the nature of the nitrogen substitution (benzyl or alkyl), bodes well for further development of this new chiral catalyst platform. ${ }^{[28]}$

Table 3. Asymmetric intramolecular $\mathrm{HA}$ reaction catalyzed by $\left(R_{a}, R_{a}, S, S\right)-19$

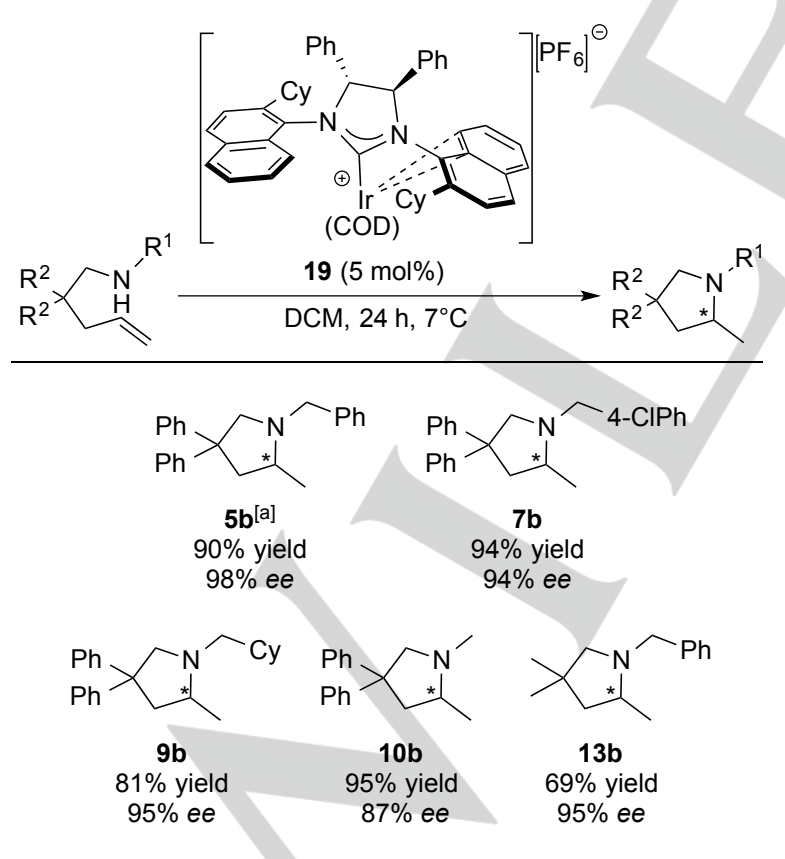

Conditions: $0.3 \mathrm{mmol}$ substrate, $5 \mathrm{~mol} \% 19,0.5 \mathrm{~mL} \mathrm{DCM}, 7^{\circ} \mathrm{C}$, $24 \mathrm{~h}$. Isolated yields. The ee was determined by ${ }^{1} \mathrm{H}$ NMR spectroscopy. ${ }^{\text {[a] }} 2 \mathrm{~mol} \% 19$ was used, ee was determined by HPLC.

\subsection{Possible deactivation pathway of $[(\mathrm{NHC}) \operatorname{Ir}(\mathrm{COD})]\left[\mathrm{PF}_{6}\right]$ catalysts in DCM.}

As outlined above, we did see some differences in behavior of both anti-4b and enantiopure $\left(R_{a}, R_{a}, S, S\right)-19$ in terms of suitability of the solvent, with anti-4b performing better in ${ }^{\mathrm{t}} \mathrm{BuOH}$ than dichloromethane, especially for the less reactive substrates. While a more thorough investigation is needed to fully understand how the solvent influences the outcome of these HA reactions, a preliminary result that we were able to gather with anti-4b in DCM in the presence of a stoichiometric amount of triethylamine is relevant and noteworthy. Scheme 3 shows that anti-4b rapidly decomposes in the presence of this simple tertiary amine in DCM to give good isolated yields of the starting chloride complex anti-2b, which is not catalytically active in the intramolecular HA reaction described here. It is known that triethylamine (and other amines) can be alkylated by methylene chloride (Menshutkin reaction), ${ }^{[29]}$ but the reaction is normally negligible due to its very slow reaction rate (half-live of over a month for triethylamine). ${ }^{[30]}$ The reactivity in Scheme 3 shows that anti-4b is able to greatly accelerate this transformation. ${ }^{[31]}$ While more detailed information will have to be gathered in the future with regards to similar reactivity with amines that are substrates and/or products of the intramolecular HA protocol, it seems likely that this decomposition pathway is operative to some degree in the overall catalytic transformation described here.

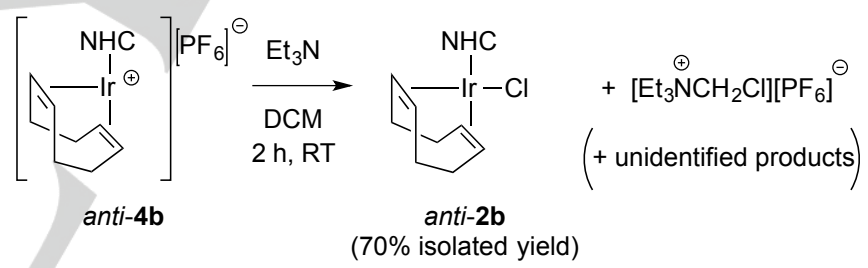

Scheme 3. Reactivity of $\mathrm{Et}_{3} \mathrm{~N}$ with $\mathrm{DCM}$ accelerated by anti-4b

\section{Conclusions}

In conclusion, we have synthesized unusual $[(\mathrm{NHC}) \operatorname{lr}(\mathrm{COD})]\left[\mathrm{PF}_{6}\right]$ complexes where an additional binding interaction is present. The interaction stabilizes an otherwise very reactive 14-electron $\operatorname{Ir}(I)$ species and at the same time significantly increases the steric bulk of the ligand, as quantified by steric quadrant maps. The interaction also leads to a sideways tilt of the NHC-M bond that translates into a large upfield shift of the carbene carbon signal. DFT calculations have allowed us to show that this is a general phenomenon of such tilted NHCs. It can be attributed to the paramagnetic component of the isotropic shielding and is due to the misalignment of the bonding lobes forming the NHC-M $\sigma$-bond. The non-destructive nature of the wingtip interaction is at the heart of the complexes' excellent performance when employed as catalysts in the intramolecular HA reaction. Notably, first results employing an enantiopure version of our $\mathrm{NHC}$ led to a catalyst that provided excellent enantioselectivities in the asymmetric version of this 
HA. Because the catalytic results here are a first for the monodentate NHC ligand class, further investigations will be needed to understand how steric and electronic tuning of the $\mathrm{NHC}$ moiety affects catalytic performance. A major goal of these studies will be to conjure up chiral catalyst systems that show similarly high reactivity to anti-4b. Detailed mechanistic studies will also be conducted to shed light onto the catalytic reaction cycle and will have to take into account our preliminary, intriguing data on solvent participation to catalyst decomposition.

\section{Acknowledgements}

G.S. thanks UWA for an International Postgraduate Research Scholarship. R.D. thanks the Australian Research Council for generous funding (FT130101713). The Centre for Microscopy, Characterisation \& Analysis at UWA is thanked for providing facilities and assistance. L.C. thanks the King Abdullah University of Science and Technology for financial support.

\section{Keywords: $\mathrm{NHCs} \cdot$ Iridium $・ \mathrm{DFT} \cdot$ Hydroamination}

[1] For books and reviews see: (a) New Trends in Cross-Coupling: Theory and Applications (Ed.: T. Colacot), RSC: Cambridge, 2015. (b) P. G Gildner, T. J. Colacot, Organometallics 2015, 34, 5497. (c) F. Izquierdo S. Manzini, S. P. Nolan, Chem. Commun. 2014, 50, 14926. (d) C Valente, S. Çalimsiz, K. H. Hoi, D. Mallik, M. Sayah, M. G. Organ, Angew. Chem. 2012, 124, 3370; Angew. Chem. Int. Ed. 2012, 51, 3314 For selected recent examples see: (e) N. H. Park, E. V. Vinogradova, D. S. Surry, S. L. Buchwald, Angew. Chem. 2015, 127, 8377; Angew. Chem. Int. Ed. 2015, 54, 8259. (f) S. Sharif, R. P. Rucker, N. Chandrasoma, D. Mitchell, M. J. Rodriguez, R. D. J. Froese, M. G. Organ, Angew. Chem. 2015, 127, 9643; Angew. Chem. Int. Ed. 2015 54, 9507. (g) D. Maiti, B. P. Fors, J. L. Henderson, Y. Nakamura, S. L. Buchwald, Chem. Sci. 2011, 2, 57.

[2] For an excellent recent review on the topic of catalyst decomposition, see: R. H. Crabtree, Chem. Rev. 2015, 115, 127.

[3] For books on the subject: (a) N-Heterocyclic Carbenes in Synthesis (Ed.: S. P. Nolan), Wiley-VCH: Weinheim, 2006. (b) N-Heterocyclic Carbenes in Transition Metal Catalysis (Eds.: F. Glorius, S. BelleminLaponnaz), Springer: Berlin, 2007. (c) N-Heterocyclic Carbenes in Transition Metal Catalysis and Organocatalysis (Ed.: C. S. J. Cazin), Springer: Berlin, 2010. (d) N-Heterocyclic Carbenes: From Laboratory Curiosities to Efficient Synthetic Tools (Ed.: S. Díez-González), RSC: Cambridge, 2011. (e) N-Heterocyclic Carbenes (Ed.: S. P. Nolan), Wiley-VCH: Weinheim, 2014. For a short account, see: (f) M. N. Hopkinson, C. Richter, M. Schedler, F. Glorius, Nature 2014, 510, 485.

[4] For selected reviews on the subject: (a) S. Diez-Gonzalez, N. Marion, S. P. Nolan, Chem. Rev. 2009, 109, 3612. (b) G. C. Vougioukalakis, R. H. Grubbs, Chem. Rev. 2010, 110, 1746. (c) F. Wang, L. J. Liu, W. Wang, S. Li, M. Shi, Coord. Chem. Rev. 2012, 256, 804. NHC synthesis: (d) P. de Frémont, N. Marion, S. P. Nolan, Coord. Chem. Rev. 2009, 253, 862 (e) L. Benhamou, E. Chardon, G. Lavigne, S. Bellemin-Laponnaz, V. César, Chem. Rev. 2011, 111, 2705. NHC stability and reactivity: (f) C. M. Crudden, D. P. Allen, Coord. Chem. Rev. 2004, 248, 2247. M-NHC bond: (g) H. Jacobsen, A. Correa, A. Poater, C. Costabile, L. Cavallo, Coord. Chem. Rev. 2009, 253, 687.

[5] For first reports on their synthesis and characterization: (a) A. J. Arduengo, H. V. R. Dias, R. L. Harlow, M. Kline, J. Am. Chem. Soc. 1992, 114, 5530. (b) A. J. Arduengo, J. R. Goerlich, W. J. Marshall, J.
Am. Chem. Soc. 1995, 117, 11027. (c) A. J. Arduengo, R. Krafczyk, R. Schmutzler, H. A. Craig, J. R. Goerlich, W. J. Marshall, M. Unverzagt, Tetrahedron 1999, 55, 14523.

[6] (a) X. Luan, R. Mariz, M. Gatti, C. Costabile, A. Poater, L. Cavallo, A. Linden, R. Dorta, J. Am. Chem. Soc. 2008, 130, 6848. (b) L. VieillePetit, X. Luan, R. Mariz, S. Blumentritt, A. Linden, R. Dorta, Eur. J. Inorg. Chem. 2009, 1861. (c) L. Vieille-Petit, X. Luan, M. Gatti, S. Blumentritt, A. Linden, H. Clavier, S. P. Nolan, R. Dorta, Chem. Commun. 2009, 3783. (d) L. Wu, E. Drinkel, F. Gaggia, S. Capolicchio, A. Linden, L. Falivene, L. Cavallo, R. Dorta, Chem. Eur. J. 2011, 17, 12886. (e) M. Gatti, L. Wu, E. Drinkel, F. Gaggia, S. Blumentritt, A. Linden, R. Dorta, Arkivoc 2011, 6, 176.

[7] Examples of neutral (NHC) $\operatorname{lr}(\mathrm{COD}) \mathrm{X}(\mathrm{X}=$ anionic ligand $)$ and $[(\mathrm{NHC}) \operatorname{Ir}(\mathrm{COD}) \mathrm{L}]^{+}(\mathrm{L}=$ neutral 2-electron donor) are abundant in the literature, see examples reviewed in refs 3 and 4 as well as chapter 3 in: Iridium Complexes in Organic Synthesis (Eds.: L. A. Oro, C. Claver), Wiley-VCH: Weinheim, 2009

[8] For recent, excellent reviews on the HA reaction: (a) T. E. Müller, M. Beller, Chem. Rev. 1998, 98, 675. (b) K. C. Hultzsch, Adv. Synth. Catal. 2005, 347, 367. (c) T. E. Müller, K. C. Hultzsch, M. Yus, F. Foubelo, M. Tada, Chem. Rev. 2008, 108, 3795. (d) A. L. Reznichenko, K. C. Hultzsch, Top. Organomet. Chem 2013, 43, 51. (e) N. Nishina, Y. Yamamoto, Top. Organomet. Chem. 2013, 43, 115. (f) J. Hannedouche, E. Schulz, Chem. Eur. J. 2013, 19, 4972. (g) L. Huang, M. Arndt, K. Gooßen, H. Heydt, L. J. Gooßen, Chem. Rev. 2015, 115, 2596. (h) E. Bernoud, C. Lepori, M. Mellah, E. Schulz, J. Hannedouche, Catal. Sci. Technol. 2015, 5, 2017.

[9] For the most relevant recent literature: (a) A. Takemiya, J. F. Hartwig, J Am. Chem. Soc. 2006, 128, 6042. (b) Z. Liu, J. F. Hartwig, J. Am. Chem. Soc. 2008, 130, 1570. (c) K. D. Hesp, M. Stradiotto, Org. Lett. 2009, 11, 1449. (d) C. Metallinos, J. Zaifman, L. Van Belle, L. Dodge, M. Pilkington, Organometallics 2009, 28, 4534. (e) K. D. Hesp, S. Tobisch, M. Stradiotto, J. Am. Chem. Soc. 2010, 132, 413. (f) X. Shen, S. L. Buchwald, Angew. Chem. 2010, 122, 574; Angew. Chem. Int. Ed. 2010, 49, 564. (g) L. D. Julian, J. F. Hartwig, J. Am. Chem. Soc. 2010, 132, 13813. (h) Y. Kashiwame, S. Kuwata, T. Ikariya, Chem. Eur. J. 2010, 16, 766. (i) Z. Liu, H. Yamamichi, S. T. Madrahimov, J. F. Hartwig, J. Am. Chem. Soc. 2011, 133, 2772. (j) Y. Kashiwame, S. Kuwata, T. Ikariya, Organometallics 2012, 31, 8444. (k) C. Hua, K. Q. Vuong, M. Bhadbhade, B. A. Messerle, Organometallics 2012, 31, 1790.

[10] For first examples of the asymmetric version of this HA with lanthanocenes, published and studied by Marks et al. in detail, see: (a) M. R. Gagné, L. Brard, V. Conticello, M. A. Giardello, C. L. Stern; T. J. Marks, Organometallics, 1992, 11, 2003. (b) V. P. Conticello, L. Brard, M. A. Giardello, Y. Tsuji, M. Sabat, C. L. Stern, T. J. Marks, J. Am. Chem. Soc. 1992, 114, 2761. (c) M. A. Giardello, V. P. Conticello, L. Brard, M. R. Gagné, T. J. Marks, J. Am. Chem. Soc. 1994, 116, 10241. For first examples with chiral non-metallocene systems, see: (d) $\mathrm{S}$. Hong, S. Tian, M. V. Metz, T. J. Marks, J. Am. Chem. Soc. 2003, 125, 14768. (e) P. N. O'Shaughnessy, P. Scott, Tetrahedron: Asymmetry 2003, 14, 1979. (f) P. N. O'Shaughnessy, P. D. Knight, C. Morton, K. M. Gillespie, P. Scott, Chem. Commun. 2003, 1770. (g) D. V. Gribkov, K. C. Hultzsch, F. Hampel, Chem. Eur. J. 2003, 9, 4796. (h) J. Collin, J.-C. Daran, E. Schulz, A. Trifonov, Chem. Commun. 2003, 3048.

[11] For examples that feature NHCs within chelates (all of them non chiral): (a) E. B. Bauer, G T. S. Andavan, T. K. Hollis, R. J. Rubio, J. Cho, G. R. Kuchenbeiser, T. R. Helgert, C. S. Letko, F. S. Tham, Org. Lett. 2008, 10, 1175. (b) Z. G. Specht, S. A. Cortes-Llamas, H. N. Tran, C. J. Van Niekerk, C. J. Rancudo, J. A. Golen, C. E. Moore, A. L. Rheingold, T. J. Dwyer, D. B. Grotjahn, Chem. Eur. J. 2011, 17, 6606. (c) R. Zhang, Q. Xu, L. Y. Mei, S. K. Li, M. Shi, Tetrahedron 2012, 68, 3172. For an example of Au-catalyzed hydroamidation with monodentate NHCs: (d) H. Li, R. A. Widenhoefer, Org. Lett. 2009, 11, 2671.

[12] For asymmetric intermolecular HA with Ir (activated substrates): (a) R. Dorta, P. Egli, F. Zurcher, A. Togni, J. Am. Chem. Soc. 1997, 119, 
10857. (b) J. Zhou, J. F. Hartwig, J. Am. Chem. Soc. 2008, 130, 12220 (c) S. Pan, K. Endo, T. Shibata, Org. Lett. 2012, 14, 780. (d) C. S Sevov, J. Zhou, J. F. Hartwig, J. Am. Chem. Soc. 2012, 134, 11960. (e) C. S. Sevov, J. Zhou, J. F. Hartwig, J. Am. Chem. Soc. 2014, 136, 3200

[13] See the Supporting Information for further details.

[14] (a) C. A. Tolman, Chem. Rev. 1977, 77, 313. (b) A. Chianese, X. Li, M. Janzen, J. Faller, R. Crabtree, Organometallics 2003, 22, 1663. (c) R. A Kelly III, H. Clavier, S. Giudice, N. M. Scott, E. D. Stevens, J. Bordner, I. Samardjiev, C. D. Hoff, L. Cavallo, S. P. Nolan, Organometallics 2008, 27, 202. For a recent review on the electronics of NHCs: (d) D. J. Nelson, S. P. Nolan, Chem. Soc. Rev. 2013, 42, 6723.

[15] C. Y. Tang, J. Lednik, D. Vidovic, A. L. Thompson, S. Aldridge, Chem. Commun. 2011, 47, 2523.

[16] For a review on cyclometalations: (a) M. Albrecht, Chem. Rev. 2010 110,576 . For closely related, selected examples of $\mathrm{C}-\mathrm{H}$ activation of the NHC wingtips in iridium complexes, see: (b) N. M. Scott, R. Dorta, E. D. Stevens, A. Correa, L. Cavallo, S. P. Nolan, J. Am. Chem. Soc. 2005, 127, 3516. (c) C. Y. Tang, A. L. Thompson, S. Aldridge, J. Am. Chem. Soc. 2010, 132, 10578. (d) C. Y. Tang, W. Smith, A. L. Thompson, D. Vidovic, S. Aldridge, Angew. Chem. 2011, 123, 1395; Angew. Chem. Int. Ed. 2011, 50, 1359.

[17] CCDC 1433190-1433196 contain the supplementary crystallographic data for this paper. These data can be obtained free of charge from The Cambridge Crystallographic Data Centre via www.ccdc.cam.ac.uk/data_request/cif.

[18] We are aware of only one example of a fully characterized 14-electron $\operatorname{Ir}(\mathrm{I})$ species. The complex was obtained via $\mathrm{C}-\mathrm{H}$ activation/dehydrogenation of a dipp-nacnac ligand, see: W. H. Bernskoetter, E. Lobkovsky, P. J. Chirik, Organometallics 2005, 24, 6250 .

[19] For a similar iridium complex that incorporates a bulky monophosphine ligand and shows a classical $\eta^{2}$-coordination of an aryl group, see: A. R. O'Connor, W. Kaminsky, B. C. Chan, D. M. Heinekey, K. I. Goldberg Organometallics 2013, 32, 4016.

[20] For an example that shows a weaker interaction of IMes: (a) F. Wu, V. K. Dioumaev, D. J. Szalda, J. Hanson, R. M. Bullock, Organometallics 2007, 26, 5079. For related examples featuring more exotic $\mathrm{NHC}$ architectures, see: (b) N. Imlinger, K. Wurst, M. R. Buchmeiser, J. Organomet. Chem. 2005, 690, 4433. (c) Y. Zhang, D. Wang, K. Wurst, M. R. Buchmeiser, J. Organomet. Chem. 2005, 690, 5728. (d) E. L. Kolychev, S. Kronig, K. Brandhorst, M. Freytag, P. G. Jones, M. Tamm, J. Am. Chem. Soc. 2013, 135, 12448.

[21] Some shifting in the carbene signal when going from neutral to cationic complexes is to be expected, see also: O. Torres, M. Martín, E. Sola, Organometallics 2009, 28, 863.
[22] All NMR calculations were performed with the ADF suite at the BP86 level of theory using a triple- $\zeta$ plus two polarization basis set, see Supporting Information for further details; A. Liske, K. Verlinden, H. Buhl, K. Schaper, C. Ganter, Organometallics 2013, 32, 5269.

[23] (a) L. Benhamou, S. Bastin, N. Lugan, G. Lavigne, V. César, Dalton Trans. 2014, 43, 4474. (b) V. César, S. Bellemin-Laponnaz, L. H. Gade, Eur. J. Inorg. Chem. 2004, 17, 3436.

[24] (a) S. V. C. Vummaleti, D. J. Nelson, A. Poater, A. Gómez-Suárez, D. B. Cordes, A. M. Z. Slawin, S. P. Nolan, L. Cavallo, Chem. Sci. 2015, 6 1895. (b) H. Jacobsen, A. Correa, C. Costabile, L. Cavallo, J. Organomet. Chem. 2006, 691, 4350.

[25] (a) A. J. Arduengo, D. A. Dixon, K. K. Kumashiro, C. Lee, W. P. Power, K. W. Zilm, J. Am. Chem. Soc. 1994, 116, 6361. (b) G. Schreckenbach T. Ziegler, J. Phys. Chem. 1995, 99, 606. (c) G. Schreckenbach, T. Ziegler, Int. J. Quantum Chem. 1997, 61, 899.

[26] (a) X. Luan, R. Mariz, C. Robert, M. Gatti, S. Blumentritt, A. Linden, R. Dorta, Org. Lett. 2008, 10, 5569. (b) X. Luan, L. Wu, E. Drinkel, R. Mariz, M. Gatti, R. Dorta, Org. Lett. 2010, 12, 1912. (c) L. Wu, L. Falivene, E. Drinkel, S. Grant, A. Linden, L. Cavallo, R. Dorta, Angew. Chem. 2012, 124, 2924; Angew. Chem. Int. Ed. 2012, 51, 2870.

[27] For catalytic systems providing $>90 \%$ ee for at least two pyrrolidinetype products; with rare earth/group 4 metals: (a) D. V. Gribkov, K. C. Hultzsch, F. Hampel, J. Am. Chem. Soc. 2006, 128, 3748. (b) M. C Wood, D. C. Leitch, C. S. Yeung, J. A. Kozak, L. L. Schafer, Angew. Chem. 2007, 119, 358; Angew. Chem. Int. Ed. 2007, 46, 354. (c) K. Manna, S. Xu, A. D. Sadow, Angew. Chem. 2011, 123, 1905; Angew. Chem. Int. Ed. 2011, 50, 1865. (d) K. Manna, M. L. Kruse, A. D. Sadow, ACS Catal. 2011, 1, 1637. (e) K. Manna, W. C. Everett, G. Schoendorf, A. Ellern, T. L. Windus, A. D. Sadow, J. Am. Chem. Soc. 2013, 135, 7235. (f) K. Manna, N. Eedugurala, A. D. Sadow, J. Am. Chem. Soc. 2015, 137, 425. (g) X. Zhou, B. Wei, X.-L. Sun, Y. Tang, Z. Xie, Chem Commun. 2015, 51, 5753. With Mg: (h) X. Zhang, T. J. Emge, K. C. Hultzsch, Angew. Chem. 2012, 124, 406; Angew. Chem. Int. Ed. 2012, $51,394$.

[28] Reference $9 f$ is the only other report on enantioselective intramolecular $\mathrm{HA}$ of such substrates with a late-transition metal (Rh, between $62 \%$ and $91 \%$ ee).

[29] N. Menshutkin, Z. Phys. Chem. 1890, 6, 41

[30] G. O. Nevstad, J. Songstad, Acta Chem. Scand. B 1984, 38, 469.

[31] For a recent paper that shows similar acceleration/facilitation of this reaction, in this case through incorporation of the tertiary amine into a macrocycle, see: J.-J. Lee, K. J. Stanger, B. C. Noll, C. Gonzalez, M. Marquez, B. D. Smith, J. Am. Chem. Soc. 2005, 127, 4184. 


\section{FULL PAPER}

Tilt and Turn(over): An additional binding interaction that tilts the $\mathrm{N}$ heterocycle of a particular class of monodentate NHCs is key to the synthesis of cationic $\operatorname{Ir}(\mathrm{I})$ species. Such tilting leads to a significant upfield shift of the carbene signal and DFT calculations show this to be a general phenomenon for NHCs. When employed as catalysts in the intramolecular hydroamination, these compounds show excellent activity and enantioselectivity.

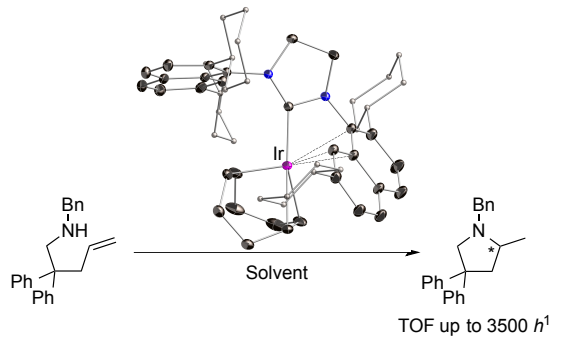

Gellért Sipos, Arnold Ou, Brian W. Skelton, Laura Falivene, Luigi Cavallo, * Reto Dorta*

Page No. - Page No.

Unusual NHC-Iridium(I) Complexes and their Use in the Intramolecular Hydroamination of Unactivated Aminoalkenes 